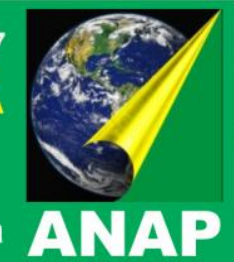

\title{
A CULTURA DO MELÃO: UMA ABORDAGEM ACERCA DA CADEIA PRODUTIVA NO AGROPÓLO MOSSORÓ - ASSÚ/RN
}

\author{
Maria da Conceição Freitas Moura ${ }^{1}$ \\ Ludimilla Carvalho Serafim de Oliveira ${ }^{2}$ \\ Shamyra Geórgia de Azevedo e Silva ${ }^{3}$
}

RESUMO: O melão (Cucumis melo L.) é uma planta anual, herbácea, diplóide, pertencente à família das Cucurbitáceas, tem expressiva representatividade na pauta de exportações de frutos brasileiros. Por se adaptar as condições climáticas da região Semi-Árida os frutos são cultivados em alguns estados do Nordeste, os dois principais agropólos são: o baixo Jaguaribe no Ceará e o Mossoró/Assú no Rio Grande do Norte. A presente pesquisa teve como objetivo mostrar os impactos ambientais ocasionados pela atividade produtiva do melão no agropólo Mossoró/Assú, este localizado na mesorregião Oeste potiguar no Estado do Rio Grande do Norte. Os processos metodológicos da pesquisa basearam-se em visitas e observações em campo, atrelando as formas de manuseio do preparo firmado do solo para a implantação dessa cultura, além do levantamento de dados da literatura. Os resultados mostraram impactos ambientais no cenário dessa atividade, começando pelo desmatamento, preparo do solo e os tratos culturais, este abrangendo em especial, o uso dos agrotóxicos, que além de contaminar o ambiente, podem causar sérios problemas a saúde humana, seja na aplicação desses produtos no campo ou nos resíduos alimentares. Perante os fatos discutidos a cerca da exploração agrícola no agropólo Mossoró-Assú, é observada uma forma danosa de como é trabalhado o ambiente cultivável, mesmo com as vantagens socioeconômica, mas é severa a maneira de se manejar o ambiente o qual se cultiva o melão, dessa forma, é visto algumas alternativas que minimizam essas atividades impactantes na cadeia produtiva do melão no agropólo em estudo.

Palavras-chave: Cucumis melo L, Impactos ambientais, Sustentabilidade.

\footnotetext{
${ }^{1}$ Mestranda em Fitotecnia - UFERSA, e-mail: ceicaomoura@hotmail.com

${ }^{2}$ Professora do Departamento de Agrotecnologia e Ciências Sociais - UFERSA, e-mail: ludimillaoliveira@globo.com

${ }^{3}$ Graduanda em Agronomia - UFERSA, e-mail: shamyrageorgia@hotmail.com
} 


\section{INTRODUÇÃO}

O melão (Cucumis melo L.) pertence à família das Cucurbitáceas é uma planta anual, herbácea, diplóide ( $2 n=2 x=24$ cromossomos) possuindo um sistema radicular superficial e praticamente sem raízes adventícias; apresenta baixa capacidade de regeneração quando danificado, com caule de crescimento rasteiro ou prostrado, e nós com gemas, sendo que dessas gemas desenvolvem-se gavinhas, folhas, novos caules ou ramificações. (FONTES e PUIATTI, 2005).

Para muitos autores o melão é uma planta alógama ${ }^{4}$, pertencente à família das Curcubitáceas, porém segundo Mathew et al (1986) há registro que se trata de uma planta de reprodução mista. Alguns frutos são oriundos de polinização cruzada e outros da autapolinização.

É uma espécie exigente em temperaturas que de acordo com Nicolas et al. (1989) as mesmas variam de $28{ }^{\circ} \mathrm{C}$ a $32{ }^{\circ} \mathrm{C}$ para a germinação das sementes, $20{ }^{\circ} \mathrm{C}$ a $32{ }^{\circ} \mathrm{C}$ para a floração e $25{ }^{\circ} \mathrm{C}$ a $30{ }^{\circ} \mathrm{C}$ para o desenvolvimento vegetativo.

Essas espécies da família das Cucurbitáceas são cultivadas em várias regiões do mundo, devido a sua fácil adaptação a vários solos e clima. Além do mais tem uma importância econômica e social, permitindo a geração de emprego e renda no Semi-Árido brasileiro.

O Nordeste Brasileiro vem se mostrando bastante favorável ao cultivo dessa cultura (Cucumis melo L.), destacando-se com uma produção nacional em torno de 99,93\%, tendo os Estados do Ceará e Rio Grande do Norte com uma participação de aproximadamente $60,88 \%$ e $37,48 \%$, respectivamente. (MDICE, 2011).

Dessa forma, há uma exploração nas áreas de cultivo, para o trabalho nas etapas necessárias para firmar a cultura ao solo, gerando assim impactos ao meio, através do desmatamento, uso intensivo de maquinários agrícolas, fertilizantes ${ }^{5}$ e produtos químicos, que afugenta ou até elimina a população de inimigos naturais, que antes era responsável

\footnotetext{
${ }^{4}$ Planta de fecundação cruzada. (FERMENT et al, 2009).

${ }^{5}$ É toda substância mineral ou orgânica, natural ou sintética, que fornece um ou mais nutrientes a planta. (FERTILIZANTES...,2011).
} 


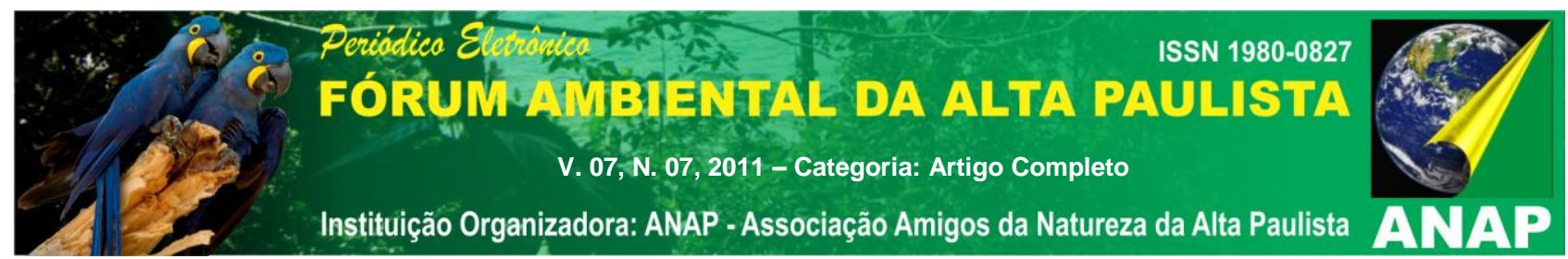

pelo equilíbrio ecológico, além de trabalhar o monocultivo. É entendido, pois, um desequilíbrio resultante da ação do homem sobre o meio ambiente.

Porém, com as determinações impostas pela legislação ambiental (lei 6.938/81) sobre a preocupação com o meio ambiente, há a necessidade de trabalhar de modo produtivo e sustentável, basta adequar aos modos corretos de produção, sempre com a finalidade de produzir em grande escala para a população e obedecer aos requisitos ambientais, pois é preciso manejar o meio ambiente de forma segura para que possa garantir o alimento e uma vida saudável e de qualidade para os nossos descendentes.

A forma da sustentabilidade atrelada ao cultivo do melão, fossa os produtores a trabalharem de acordo com a exigência do mercado externo, adequando os seus cultivos de forma que possa ser aceito, para isso busca as exigência das boas práticas agrícolas (BPAs), como o GlobalGrap.

Além do mais Nunes et al (2006) faz uma abordagem do agronegócio, estado, meio ambiente e economia com a sustentabilidade da atividade meloeira, segundo esses autores, a exploração dessa atividade é dita como insustentável, pois o uso expressivo dos produtos químicos e a exploração de poços artesianos profundos vêm modificando a cada dia o sistema agrícola.

Partindo das discussões a cerca do cultivo do meloeiro, o presente trabalho teve como objetivo mostrar os impactos ambientais ocasionados pela atividade produtiva do melão (Cucumis melo L.) no agropólo Mossoró/Assú/RN.

\section{METODOLOGIA}

Para o levantamento das principais questões ambientais relacionada à atividade do meloeiro, buscou-se averiguar em campo, através de visitas e observações os processos produtivos dessa cultura, em fazendas produtoras de melão pertencentes ao agropólo Mossoró-Assú/RN, o qual se encontra na mesorregião Oeste potiguar no Nordeste Brasileiro, também enriqueceu essa pesquisa com dados bibliográficos, mencionando informações sobre os aspectos da cadeia produtiva do melão no referido agropólo.

\section{ORIGEM DO MELÃO}




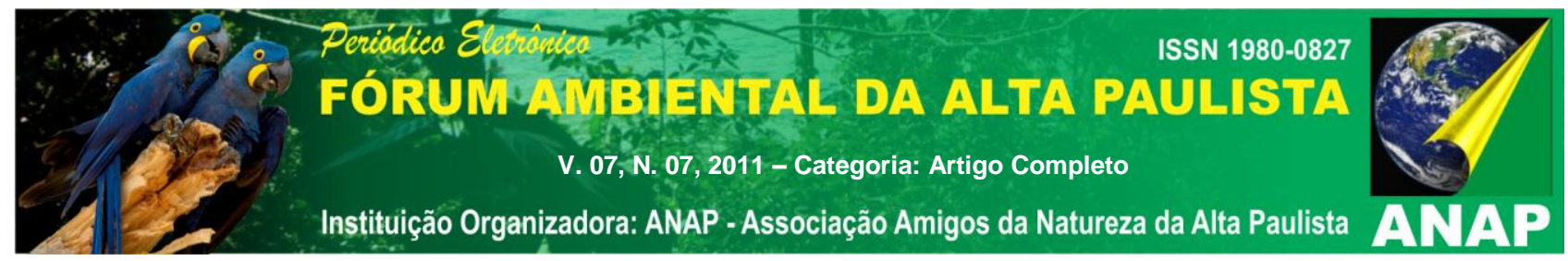

O melão é uma planta polimórfica pertencente à família das Curcubitáceas e ao gênero Cucumis. Essa cultura é bastante antiga e acredita-se que o centro de origem são as regiões tropicais e subtropicais da África, difundindo-se dessa região para a Índia e Ásia. (SEYMOUR \& MCGLASSON, 1993). Informações estas se assemelham com Simmonds (1976), a qual afirma que o melão é originado da África, espalhando-se para a Índia e posteriormente para outras regiões.

Atualmente são conhecidas mais de quarenta espécies do gênero Cucumis, todos nativos das regiões tropicais e subtropicais da África, e por essas evidências, pode-se considerar que o melão tenha essa mesma origem. (WHITAKER e DAVIS, 1962; FERREIRA et al., 1982).

Conforme Karchi (2000) a introdução dos melões na Ásia e no Oriente Médio ocorreu por volta de 2000 a 1500 a.C., e sua exploração resultou na formação de vários centros de origem secundários, como a Índia, Irã, Turquia, China e as repúblicas asiáticas.

De acordo com dados da literatura, o melão foi introduzido na Ásia em época bastante remota. O consumo do melão tornou-se popular a partir do século $\mathrm{V}$ na Espanha, e na Itália o seu consumo já era bastante conhecido, por volta do terceiro século, já na França a introdução ocorreu por volta do século XVI. (PEDROSA, 1997).

Esta amplitude de cultivo em diversas regiões é o resultado de uma grande variabilidade genética que tem permitido a adaptação de diferentes tipos de melão em diversas condições agronômicas, de tal forma que hoje podemos encontrar em todo o mercado mundial, melão com diferentes formatos, cores e aroma. (DEULOFEU, 1997).

O cultivo comercial do melão no Brasil, de acordo com dados da CEAGESP (2011) teve início na década de 60, com a introdução no estado de São Paulo e Rio Grande do Sul, mas com produção limitante, devido os fatores climáticos oferecidos por essas regiões. A condição climática adaptativa para esta cultura iniciou-se nos anos 80 , na região nordeste, que hoje domina a produção, tendo os Estados do Ceará e Rio Grande do Norte como os dois maiores produtores dessa olerícola, formando pólos de produção, como o baixo Jaguaribe e o agropólo Mossoró-Assú, respectivamente. Pois, a grande vantagem dessa região no cultivo do meloeiro é a pequena ocorrência de chuvas e a melhor qualidade dos frutos. 


\section{IMPORTÂNCIA SOCIOECONÔMICA DO MELÃO}

Por dispor de altas tecnologias e conhecimentos capazes de dar suporte na qualidade e quantidade na produção do meloeiro, o Brasil abastece o mercado interno e externo, gerando emprego e renda para a população do Semi-Árido Nordestino, tendo a participação dos pequenos, médios e grandes produtores, na comercialização desta cultura.

Destaca-se o Baixo Jaguaribe no Ceará, o agropólo Mossoró-Assú no Rio Grande do Norte, e a Chapada do Apodi em ambos os Estados, sendo responsáveis pela maior produção de melão da região Nordeste. (DIAS et al, 1998).

De acordo com Nachreiner et al (2002) o diferencial do agropólo Mossoró-Assú é por dispor de condições para poder determinar no mercado o preço, em virtude de apresentar empresas de grande porte, produção em larga escala e a alta qualidade dos produtos.

Esse agropólo é localizado na mesorregião Oeste Potiguar no Estado do Rio Grande do Norte, abrangendo 8 municípios, dos quais, Baraúna, Grossos, Mossoró, Tibau, Assú, Apodi, Gov-Dix-Sept Rosado e Upanema, compondo uma área total de $8.107 \mathrm{Km}^{2}$. (IBGE, 2010).

A região é banhada pelas bacias Piranhas/Assú e Apodi/Mossoró, encontrando a barragem Armando Ribeiro Gonçalves e a barragem de Santa Cruz no Apodi, ambas com capacidade para 2,4 bilhões de $\mathrm{m}^{3}$ e 600 milhões de $\mathrm{m}^{3}$ de água, respectivamente. (ARAÚJJO, 2009). Dando dessa forma, capacidade para o desenvolvimento da fruticultura, pela facilidade da captação de água nos respectivos reservatórios.

O melão é a fruta brasileira que tem se destacado nas duas últimas décadas com relação às exportações, passando de 50,7 mil toneladas em 1989, para mais de 211,8 mil toneladas, em 2008, pois na maioria das safras, cerca de $40 \%$ da produção vai para 0 mercado externo, e pouco menos de $5 \%$ é das outras culturas que se destina a exportação. (BRASIL, 2010).

Conforme Carvalho (1996) a tendência mundial para o agronegócio da cultura do melão é de crescimento, pois o acréscimo no consumo dessa fruta se manteve acima de 


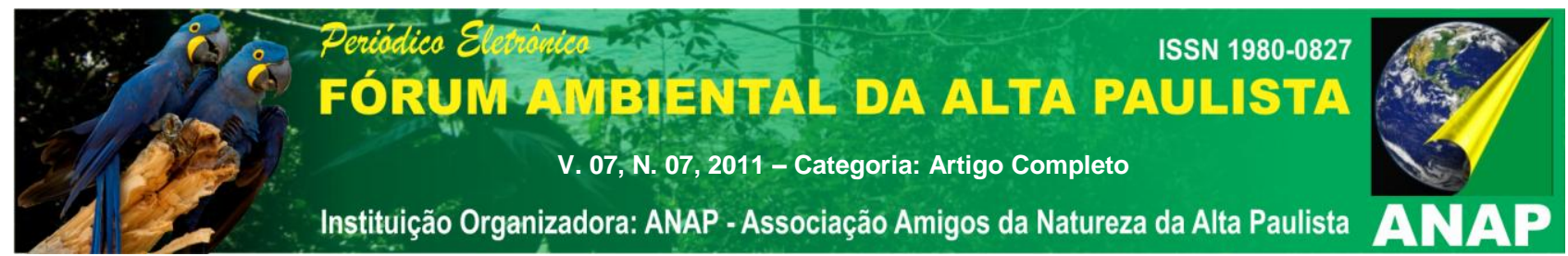

$4 \%$ nos últimos anos. Somente na Europa, o consumo cresceu 8,2\% ao ano, na década de 1980, aumentando para 10,7\% ao ano na década de 1990 .

De acordo com Aragão (2011) no cenário internacional, o melão no ano de 2007, teve pouca representabilidade em termos de cultivo e de produção. Pois, segundo dados da FAO (2010) o Brasil foi apenas o décimo segundo em produção e área plantada e o vigésimo terceiro em produtividade, porém destacando-se nas exportações, assumindo o segundo lugar.

Atualmente segundo dados do Ministério do Desenvolvimento Indústria e Comercio Exterior (2011) a região nordeste é responsável por 99,93\% da produção nacional de melão, destacando-se os estados do Ceará $(60,88 \%)$, Rio Grande do Norte $(37,48 \%)$, Bahia $(1,33 \%)$ e Pernambuco $(0,24 \%)$, dos quais com exceção a Bahia no ano de 2008 , foram responsáveis por 211.790 toneladas de frutos de melão para a exportação, atendendo ao mercado europeu. (IBRAF, 2010).

Essa cultura é de relevante importância sócioeconômica para o Nordeste Brasileiro, tendo alto valor comercial tanto no mercado interno, quanto para exportação. Pois de acordo com Pereira (2009) a área de cultivo destinada aos melões nobres representa cerca de $40 \%$ da área total cultivada com melões nos estados do Rio Grande do Norte e Ceará.

\section{AVALIAÇÃO DOS IMPACTOS NA CULTURA DO MELOEIRO}

O conceito de impactos e riscos ambientais surgiu no final da década de 60 , em debates realizado no congresso dos EUA, tendo como causa principal os efeitos dos derrames de petróleo e a Guerra do Vietan, e esse debate ambientalista culminou na "Carta Magna do Movimento Ambientalista" que veio a ser o NEPA. (FRANCO, 2001).

O NEPA, portanto, criou o EIS (Declaração de Impacto Ambiental) que tinha como objetivo prevenir impactos ocasionados pelo processo do desenvolvimento. Dessa forma, a legislação ambiental americana influenciou medidas de proteção ao meio ambiente, em todos os países, inclusive no Brasil, porém essas medidas aqui no Brasil se concretizaram depois da criação da Política Nacional do Meio Ambiente (Lei no 6.938/81), que no artigo 


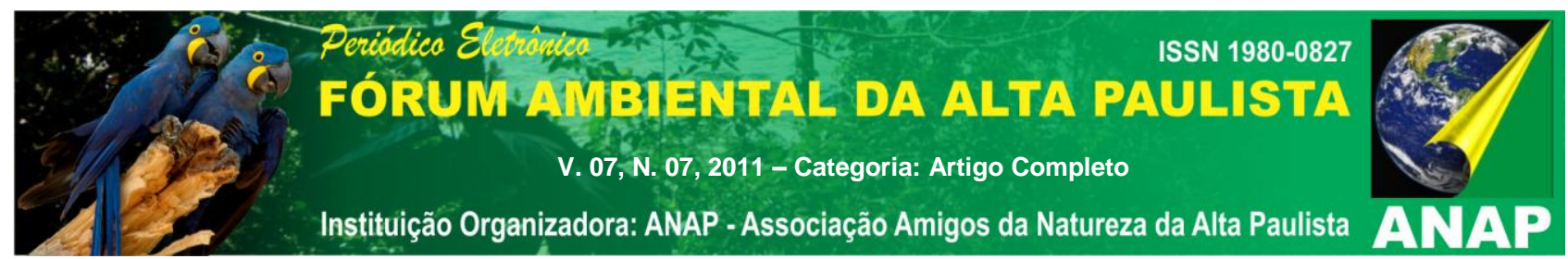

6ํㅡ, inciso 2, torna parte do SISNAMA, como o seu órgão consultivo e deliberativo, o CONAMA.

A resolução do CONAMA oo 1 de 1986, conceitua impacto como sendo:

\author{
Qualquer alteração das propriedades físicas, químicas e biológicas do meio \\ ambiente, causada por qualquer forma de matéria ou energia resultante das \\ atividades humanas, que direta ou indiretamente afetam: \\ I - a saúde, a segurança e o bem esta da população; \\ II - as atividades sociais e econômicas; \\ III - a biota; \\ IV - as condições estéticas e sanitárias do meio ambiente; \\ $\mathrm{V}$ - a qualidade dos recursos ambientais.
}

Assim, não é possível caracterizar um modelo claro e preciso do impacto ambiental, pois a magnitude do impacto ressalta a interação entre os parâmetros ambientais e dos ecossistemas, ou seja, a capacidade que o ambiente tem em persistir na presença da influência a que esta sendo submetido, em termos gerais, deve-se levar em conta como esses ecossistemas se recupera e retorna ao seu estado de equilíbrio, após o término de uma atividade impactante.

Dessa forma, cabe salientar a importância de se planejar qualquer atividade que venha a executar e alterar o meio ambiente natural, partindo desse ponto, é importante entender o que vem a ser o planejamento ambiental, pois Franco (2001) menciona que o planejamento ambiental é todo o esforço da civilização em torno de conservar e preservar os recursos ambientais de um território, com vista à sua própria sobrevivência. É importante, pois, que no sistema produtivo rural haja uma organização, em que as praticas ecológicas da região possam permanecer e dar subsídio para promover o desenvolvimento sustentável.

Levando em consideração a forma de implantação do meloeiro nas áreas de cultivo, percebem-se grandes alterações no ambiente, pois sabemos que quando um ambiente natural é modificado, ele jamais retorna a sua forma como antes, ou seja, a natural. Desse modo, há o desmatamento das áreas, o preparo firmado no solo, interferindo na fauna e flora microbiana, em geral compactando o solo, e introdução de espécies (pragas) que antes tinha como habitat natural a vegetação destruída, instalando - se e atacando a cultura, e ai vem o uso dos agrotóxicos, que poluem mananciais (rios, poços, açudes e etc), e em muitos casos até o lençol freático, além do mais trabalham com o monocultivo. 


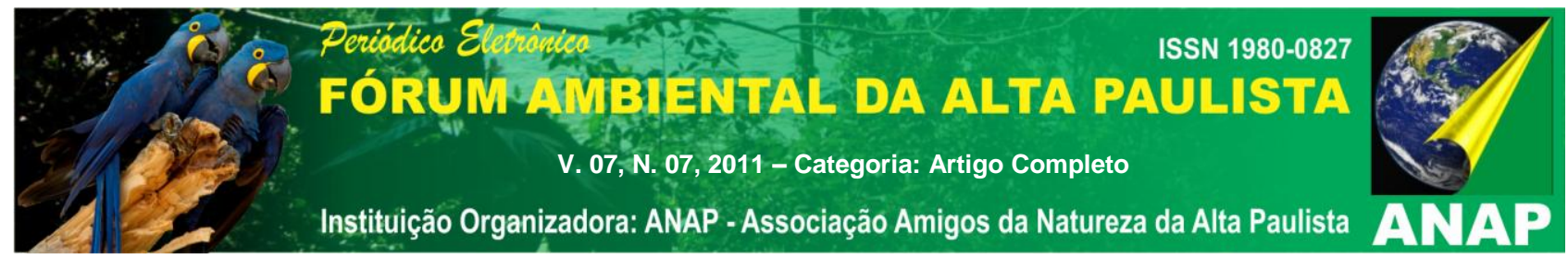

Essa alta destruição ocasionada pelo ser humano visando o econômico, gera desigualdade na forma de exploração, pois a maneira é severa, e há a necessidade de pensar em produzir, mas que reduza as alterações ocasionadas ao ambiente. Deve-se, portanto pensar em sustentabilidade, ou seja, no comportamento prudente aos recursos que o ambiente fornece, já percebido a escassez de algumas culturas no mercado, em virtude da má exploração das terras agrícolas.

Essa ideia generalizada enfatiza o Valor Máximo de Produção, daí a preocupação em trabalhar o desenvolvimento sustentável, que segundo a Comissão Mundial sobre Meio Ambiente (1991), se caracteriza como um processo de mudança, no qual a exploração de recursos, o gerenciamento dos investimentos seja compatível com o futuro, bem como com as necessidades do presente.

\section{MATRIZ DOS PRINCIPAIS IMPACTOS AMBIENTAIS CAUSADOS PELA CADEIA PRODUTIVA DO MELÃO}

\begin{tabular}{|l|c|c|}
\hline Impacto & positivo & negativo \\
\hline Desmatamento & & 2 \\
\hline Preparo do solo & & 2 \\
\hline Monocultivo & \multicolumn{2}{|c|}{} \\
\hline Tratos culturais & 2 & 2 \\
\hline Aplicação dos agrotóxicos & 2 & 1 \\
\hline Utilização do mulching & 2 & 1 \\
\hline Utilização da água para irrigação & & 1 \\
\hline Aplicação dos fertilizantes & \multicolumn{2}{|c|}{} \\
\hline
\end{tabular}

Fonte: elaborada pela autora; atribuiu-se valores variando de 1 a 3;
(1): impacto leve;
(2): impacto significativo;
(3): impacto forte.

A seguir serão discutidos os principais impactos mostrados acima

\section{1-Desmatamento das áreas}




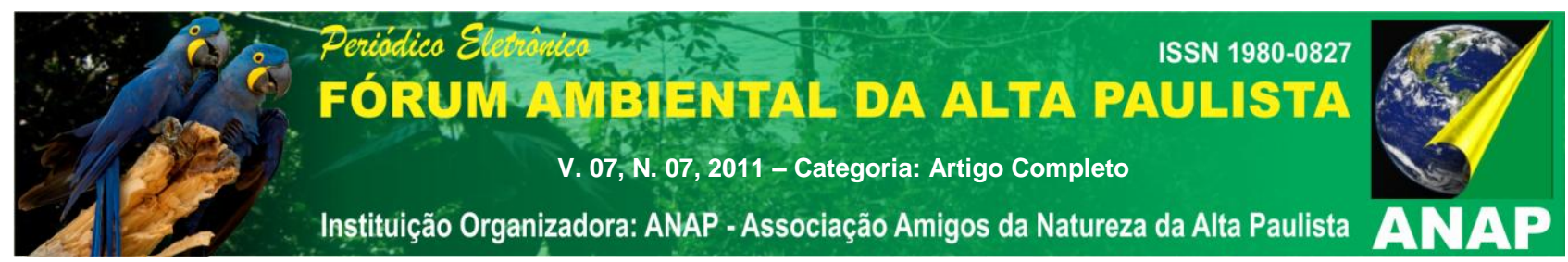

É comum observar a prática do monocultivo nas áreas que se cultiva o melão, em virtude da expansão de novas áreas para a implantação dessa Cucurbitácea, essas áreas que antes era coberta pela vegetação da caatinga, vão sendo desmatadas e incorporadas ao sistema produtivo do meloeiro, perdendo assim a biodiversidade. Frente a isso, é observável a limpeza do terreno, através da mecanização e em muitos casos queimadas, o que geram perdas do teor de matéria orgânica e a fertilidade do solo. É preocupante, pois esse desmatamento pode levar a consequências mais sérias como a desertificação, que segundo a ONU seria a degradação da terra nas zonas áridas, semiáridas e subúmidas, resultante de fatores diversos, tais como as variações climáticas e as atividades humanas. (DESERTIFICAÇÃO..., 2011).

Albreville (1949) mostra duas causa principais para a desertificação, segundo ele, seria a erosão dos solos em consequência do desmatamento e o agravamento do déficit hídrico dos solos em virtude da exposição à alta radiação solar e a atividade dos ventos secos.

\section{2- Preparo do solo para a implantação da cultura}

Feito o desmatamento das novas áreas ou o preparo das áreas cultivadas anteriormente, a camada do solo é submetida a diversos trabalhos, como a aração, gradagem e quando os solos estão muito compactados é realizada a subsolagem, em seguida é feito o sulcamento para a aplicação dos fertilizantes de fundação.

No manejo do solo, a maior preocupação esta na mecanização intensiva, o que pode gerar degradação da estrutura, formação de crosta superficial e a erosão do solo, que é considerado um sério impacto na agricultura, pois a perca dos solos agrícolas é muito grande ao longo dos anos, e a formação dos novos solos é extremamente lenta.

A erosão é dita acelerada quando é mais rápida do que os processos de formação dos solos, não permitindo que os mesmos venham a se regenerar. (ABDON, 2004). Inúmeros são os danos ocasionados pela erosão, podemos mencionar a degradação do solo, prejudicando assim, a fertilidade, o que vem a interferir nos nutrientes essenciais para a planta. Conforme Guerra (1995) existe duas fases a qual ocorre à erosão, uma 


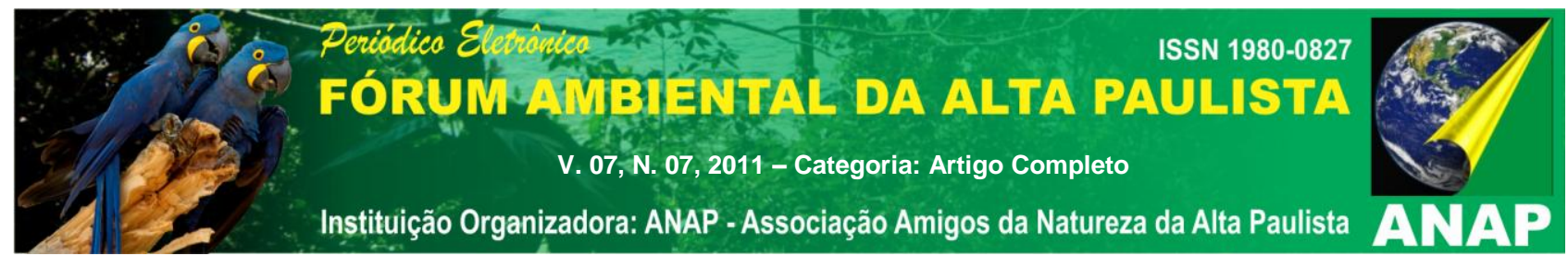

dessas seria a remoção de partículas e a outra o transporte desse material, feito pelos agentes erosivos.

\section{3-Tratos culturais após a cultura em campo}

De todos os possíveis impactos ao longo da cadeia produtiva do melão, a utilização dos agrotóxicos tem sido preocupante, pois mesmo com a fiscalização, ainda é percebida muita irregularidade na aplicação dos produtos químicos. Uma vez que, a cultura do meloeiro é altamente demandante dos defensivos agrícolas. (NEVES, et al. 2002).

De acordo com Alves Filho (2002) os agrotóxicos foram utilizados no Brasil, a partir da década de 40, inicialmente para o controle de doenças endêmicas. Somente na década de 70, foi iniciada a utilização e em muitos casos desnecessários nas plantações, surgindo assim, os primeiros casos de contaminação ambiental e problemas de saúde ocasionados pelo uso indiscriminado desses produtos. Principalmente como informa Lima (2008) intoxicação dos trabalhadores rurais, contaminação dos solos e água, além da presença de resíduos nos alimentos cultivados com esses produtos.

Segundo Alves Filho (2002) estudos comprovam que o aumento do uso dos agrotóxicos em determinadas culturas, aumentou consideravelmente o número de pragas interferentes na produtividade, além do surgimento de outras espécies igualmente danosas às culturas.

É importante ressaltar que a aplicação dos defensivos agrícolas na região em estudo, geralmente é de forma preventiva, o que leva ao uso intensivo desses produtos ao longo do cultivo, gerando dessa forma resistência de pragas às substâncias químicas existentes nesses produtos. Mas, o interessante, é que muitos produtos, embora não estejam registrados para a cultura do melão no Brasil, os produtores utilizam em suas plantações, dentre esses produtos, alguns são considerados altamente perigosos para a saúde humana como também para o meio ambiente.

Merece destaque também, o uso do plástico (Mulching) para a cobertura do canteiro, pois essa prática pode trazer interferências no ambiente, através da elevação da temperatura do solo e a redução da oxigenação, podendo assim, contribuir para a perda da biodiversidade do solo. (FIGUEIRÊDO et al, 2003). Além do mais, esses autores 


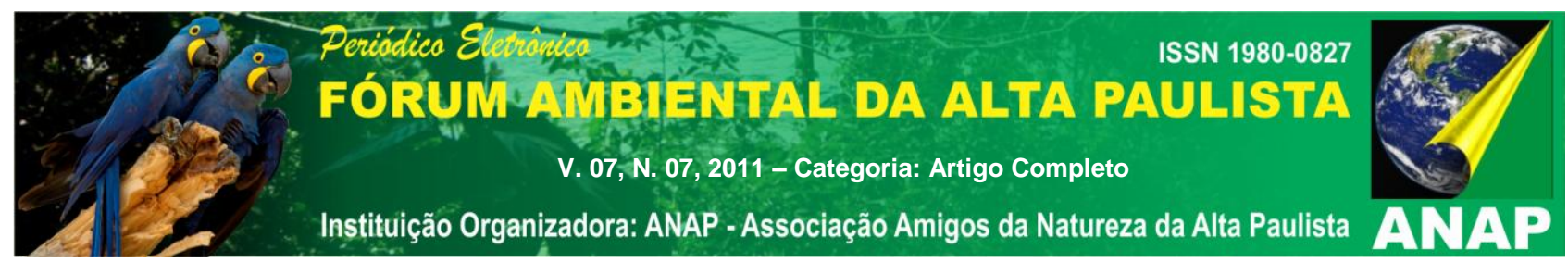

também ressalta a contaminação do solo com os restos do plástico que se rompe com os tratos culturais e com retirada do mesmo após o cultivo.

Outro fator importante para a discussão é a questão da irrigação e a fertirrigação ${ }^{6}$ dessa cultura na região em estudo, o método de irrigação utilizado pelos produtores de melão dentre os dois maiores agropólos (Mossoró - Assú /RN e Baixo Jaguaribe/ CE) é o gotejamento, que tem se mostrado eficiente no aumento da produtividade do melão, e o uso da fertirrigação, porém o grande problema, esta na concentração dos teores de cálcio e bicarbonato presentes na água, pois estão acima de 8 e $6 \mathrm{mmol}_{\mathrm{c}} / \mathrm{L}$, respectivamente. (FIGUEIRÊDO et al, 2003). Além do elevado potencial de alcalinização do solo.

Ayers e Westcot (1976) informam que a salinidade causa uma redução na permeabilidade do solo, dificultando a infiltração da água e a oxigenação do solo. Pois, é importante averiguar as condições de água nesse aqüífero, sabe-se que o uso irregular é um problema serio na Bacia Potiguar, visto a diminuição do lençol freático. Além do mais, muitos produtores utilizam fertilizantes sem a análise química e o conhecimento sobre a necessidade que a planta precisa, gerando em muitos casos contaminação do homem pelo nitrato e do ambiente com a aplicação de doses inadequadas, causando a eutrofização dos recursos hídricos.

Conforme Rodrigues (2010) a ocorrência da salinidade nos solos pode ser atribuído a causas naturais ou atividade humana. Ademais Oliveira (1997) destaca informando que nas regiões áridas e semi-áridas, a baixa precipitação e a elevada taxa de evaporação têm dificultado a lixiviação dos sais, acumulando-se em grandes quantidades e tornando um problema serio e prejudicial ao crescimento da planta.

\section{SUSTENTABILIDADE NA CULTURA DO MELÃO}

O Rio grande do Norte vem passando por contínuas mudanças desde a década de 1980, modificando os setores tradicionais que antes era a chave para a sobrevivência de diversas famílias, surgindo então em especial à fruticultura como uma atividade dinâmica e de expansão no agronegócio brasileiro. Daí esse novo statu de produção e geração de renda, enfoca o tripé economia-sociedade-natureza.

\footnotetext{
${ }^{6}$ É uma técnica de adubação em que utiliza a água da irrigação para levar nutrientes ao solo cultivado. (FERTIRRIGAÇÃO...,2011).
} 


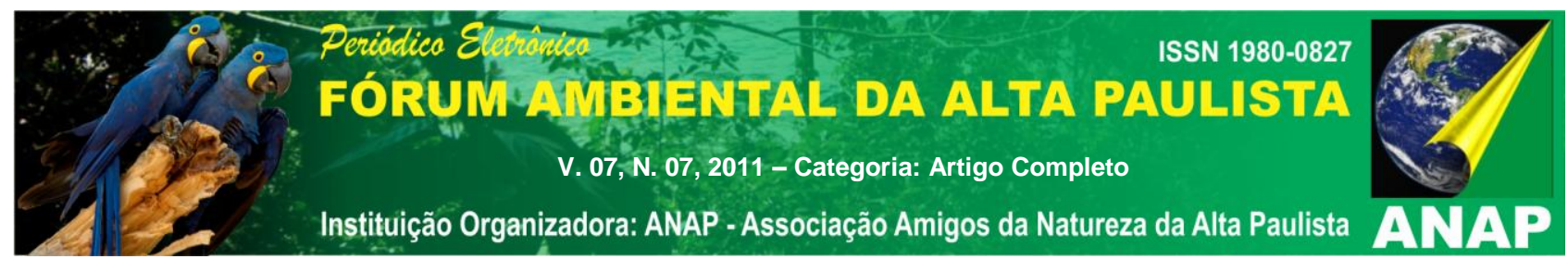

Atualmente a preocupação é produzir, mas que essa produção possa atender a população, de acordo com os parâmetros que visem minimizar as consequências negativas ocasionadas ao meio e a sociedade, e para isso tem se intensificado pesquisas com aprimoramento de tecnologias menos agressivas ao meio ambiente.

Realmente, as adversidades ambientais, as mudanças climáticas, à acentuação da desertificação, a extinção de espécies de plantas e animais, dentre outros pontos referentes à agressão a natureza, tem contribuído para que os especialistas e as pessoas em geral, busquem administrar de forma mais cuidadosa os recursos disponíveis. Para isso, Dias (2009) comenta a fundamentação de uma nova filosofia, calçada na possibilidade de compatibilizar o crescimento econômico com a conservação do meio ambiente.

Dessa forma, o setor do agronegócio do melão visa à produção, mas atendendo com respeito às formas de produzir, visto que em muitos casos o mercado externo impõe restrições na compra da fruta, exigindo o selo de qualidade, firmando assim uma obrigação em produzir para o mercado de acordo com os parâmetros impostos pelo comprador.

A adoção desses preceitos fundamenta-se a teoria do Desenvolvimento Sustentável, que atende as necessidades do presente sem comprometer a possibilidade de as gerações futuras atenderem as suas próprias necessidades. (NOSSO FUTURO COMUM, 1991, p. 46).

É importante ao longo da discussão acerca da sustentabilidade, frizar pontos referentes à mão-de-obra empregada neste setor, é percebido que o nível de escolaridade é baixo, e que os empregados firmam um contato temporário com a empresa, e ai se discutir o aspecto sustentável e socioeconômico, em termos de fortalecimento social dos municípios. Para isso Felipe (2002, p.232) enfocar a atividade provisória desses empregados. Para ele:

A percepção que temos desse processo é que a inclusão do lugar na economia moderna não significa a inclusão de todos os seus habitantes, e que a seleção também ocorre em termos de mercado de trabalho. Muitos são excluídos, mas mesmo aqueles que são convocados para trabalhar nas fazendas produtoras, ainda encontram outra dificuldade que é sazonalidade dessas atividades, obrigando os trabalhadores a buscarem outras complementaridades para a sua sobrevivência. 


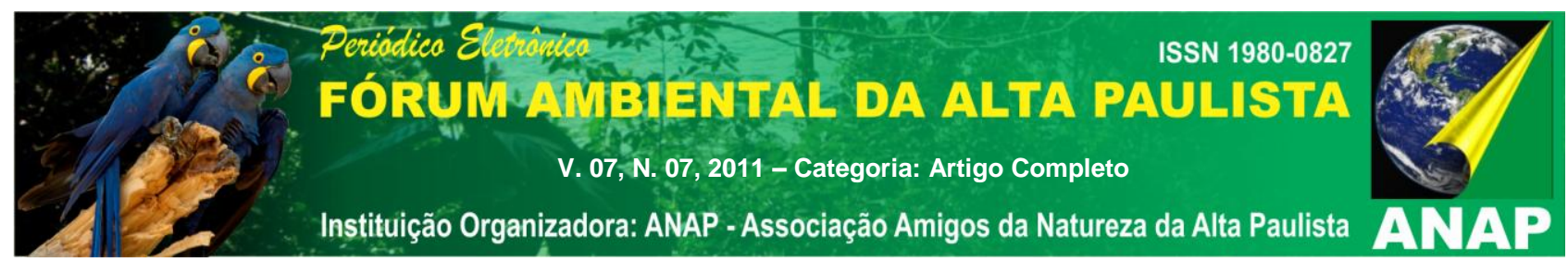

Daí um ponto importante para atrelar a sustentabilidade da produção do melão na região, a qualificação dos trabalhadores, no que se refere ao trabalho no manejo da exploração dessa cultura, para isso, é necessário uma cooperação empresa/trabalhador.

Atualmente, as empresas produtoras de melão por exigências dos seus compradores, tentam minimizar as práticas considerada de alta agressividade ao meio, trabalhando com selos de aceitação nos principais mercados compradores da fruta (melão), e esses selos garantem as boas práticas agrícolas, como exemplo, o GlobalGrap o MIP (Manejo Integrado de Pragas) e o PIM (Produção Integrada do melão).

\section{CONSIDERAÇÕES FINAIS}

Perante os fatos discutidos a cerca da exploração agrícola nos pólos de produção do melão no Nordeste Brasileiro, em especial no agropólo Mossoró-Assú/RN, percebe-se uma forma danosa de como trabalha o ambiente cultivável, mesmo com as vantagens de emprego e renda, é visto a maneira severa de se manejar o ambiente o qual se cultiva o melão, é importante frizar que toda atividade é impactante, porém há maneiras de minimizar esses impactos, algumas fazendas através de imposições dos seus importadores trabalham com selos, que impõem as boas práticas agrícolas.

Dessa forma, é observado alternativas que buscam minimizar a contaminação dos recursos ambientais, como também a saúde do homem, tendo assim, a associação do controle biológico, na cultura do melão, minimizando o uso dos agrotóxicos, também em muitas fazendas é visto o que impõem o código florestal (4.771/65) uma área destinada à reserva legal o que corresponde a $20 \%$ do total da área da propriedade rural.

\section{REFERÊNCIAS BIBLIOGRÁFICAS}

ABDON, M.de M. Os impactos ambientais no meio Físico - Erosão e Assoreamento na bacia hidrográfica do rio Taquari, MS, em decorrência da pecuária. 2004.302f. Tese (Doutor em Ciência da Engenharia Ambiental), São Paulo, 2004.

ALBREVILLE, A. Climats, forêts et desertification de l'Afrique Tropicale. Paris: Société d’editions Géographiques, Maritimes et Coloniales, 1949. 


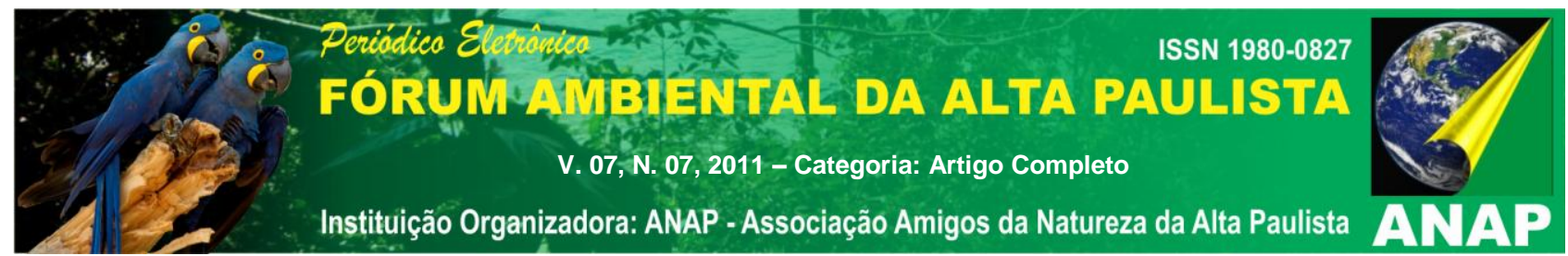

ALVES FILHO, José Prado. Uso de agrotóxico no Brasil controle social e interesses corporativos. São Paulo: annablume, 2002. 188p.

ARAÚJO, V.F.S. A Cadeia Logística do Melão: fatores intervenientes no desenvolvimento do agropólo fruticultor Mossoró/Assú. 2009, 159p. Dissertação (Mestre em Administração) - Universidade Potiguar, Natal-RN, 2009.

ARAGÃO, F. A.S. de. Divergência Genética de Acessos e Interação Genótipo x Ambiente de famílias de meloeiro. 2011.137p. Tese (Doutor em Agronomia) Universidade Federal Rural do Semi-Árido, Mossoró-RN, 2011.

AYERS, R.S.; WESTCOT, D.W. Water quality for agriculture. 1976.

BRASIL. Resolução do Conama ํo1, de 23 de janeiro de 1986. Dispõe sobre critérios básicos e diretrizes gerais para a avaliação de impacto ambiental. Disponível em: < http://www.mma.gov.br/por/conama/res/res86/res0186>Acesso em 24 jul 2011

. Ministério do Desenvolvimento Indústria e Comércio. Exportação brasileira de melões frescos. Disponível em: < http://www.aliceweb.desenvolvimento.gov.br>. Acesso em: 18 Jul. 2010.

CARVALHO, J.M. Comercialização de frutos de qualidade: a importância dos tratamentos pós-colheita. Dissertação de mestrado, Universidade Federal de Lavras. 1996. 173p.

CEAGESP. Disponível em: < http://www.ceagesp.gov.br/produtos/produtos/melao> Acesso em 04 Jul. 2011.

DEULOFEU, C. Situación y perspectivas del melón en el mundo. In: VALLESPIR, A. N., coord. Melones. Reus: Horticultura, 1997. Cap.2, p.21-24. (Compendios de Horticultura, 10).

DESERTIFICAÇÃO. Disponível em: < http://www.infopedia.pt/\$desertificacao>. Acesso em 12 jul.2011.

DIAS, Gilka da Mata. Cidade Sustentável - Fundamentos legais, política urbana, meio ambiente, saneamento básico. Natal: Ed. do autor, 2009,384p. 


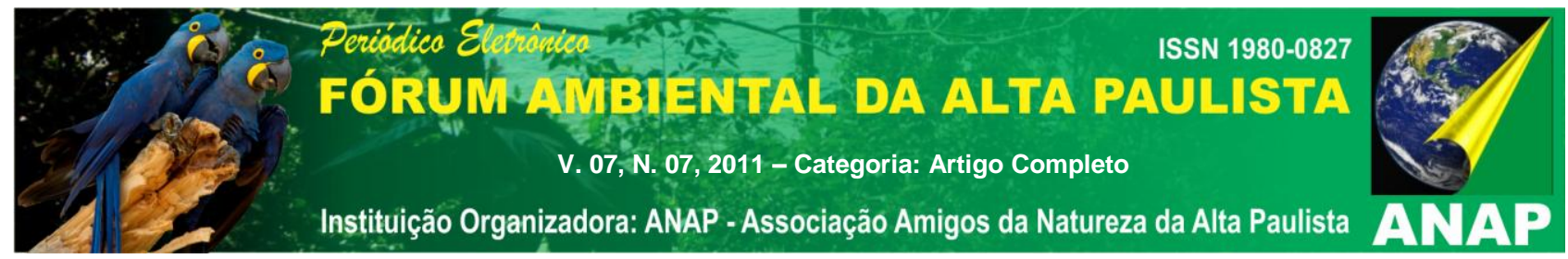

DIAS, R. de C.S. et al. Cadeia Produtiva do Melão no Nordeste. In: CASRO, A.M.G. de; LIMA, S.M.V.; GOEDERT, W. J.; FREITAS FILHO, A.de; VASCONCELHO, J.R.P. (Ed.)

Cadeias Produtivas e Sistemas Naturais: prospecção tecnológica. Brasília: EMBRAPASPI: EMBRAPA-DPD, 1998. p.441-449.

FAO (Food and Agriculture Organization). Base de Dados Agrícolas de FOASTAT-

Cultivos primários. Disponível em: <http://www.foastart.fao.org>Acesso em 20 jun 2010.

FELIPE, J. L.A. O local e o global no Rio Grande do Norte. In: VALENÇA, M. M.;GOMES, R.de C.C. (org) Globalização \& Desigualdade. Natal: A.S. editores, 2002.p.226-240.

FERMENT, G. et al. Coexistência o caso do milho. Brasília: MDA, 2009.56p.

FERREIRA, F.A.; PEDROSA, J.F.; ALVARENGA, M.A.R. Melões: Cultivares e métodos culturais. Informe Agropecuário. Belo Horizonte, v. 8, n.85, 1982. p26- 28.

FERTILIZANTES. Disponível em <http://www.fertipar.com.br/tecnico/classificacao> Acesso em 25 ago 2011.

FERTIRRIGAÇÃO. Disponível em: http://www.plantfort-fertilizantes.com.br/produtos> Acesso em 25 ago 2011.

FIGUERÊIDO, M.C. B de; ROSA, M. de F.; FREITAS, J. de A. D de. Impactos ambientais na cultura do melão. Fruit/Frutales, v.47, p.175-177, outubro 2003.

FONTES, P. C. R.; PUIATTI, M. Cultura do melão. In: FONTES, P. C. R. Olericultura: teoria e prática. UFV. Viçosa - MG, 2005. p 407-428.

FRANCO, M. de A. R. Planejamento Ambiental para a cidade sustentável. $2^{\underline{a}}$ ed. São paulo, SP: Annablume: FAPESP, 2001. 216p.

GUERRA, A.J.T. Processos Erosivos nas Encostas. In: GUERRA, A.J.T.; CUNHA, S.B.Geomorfologia: uma atualização de bases e conceitos. $2^{\mathrm{a}}$ ed. Rio de Janeiro: Bertrand Brasil. 1995. 472p. 


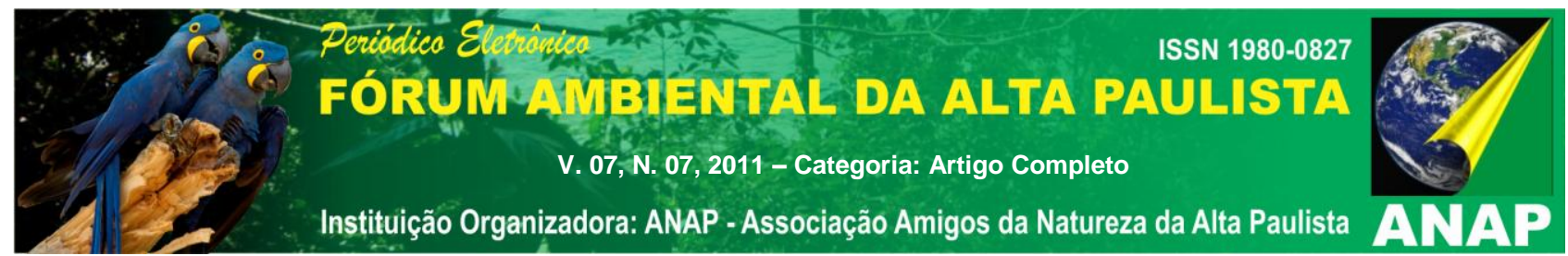

INSTITUTO BRASILEIRO DE FRUTAS. Estatísticas. Disponível em: <http:// www.ibraf.org.br/x-es/f-esta.html>. Acesso em 15 abr. 2010.

INSTITUTO BRASILEIRO DE GEOGRAFIA E ESTATISTICA (IBGE). Estatísticas. Disponível em: <http:// www.ibge.com.br>. Acesso em 20 dez 2010.

KARCHI, Z. Development of melon culture and breeding in Israel. Proceedings of $7^{\text {th }}$ EUCARPIA Meeting on Cucurbit Genetics and Breeding. Acta Horticulture, v. 510, 2000. p. 13-17.

LIMA, Paulo Júnior Paz de. Possíveis doenças físicas e mentais relacionadas ao manuseio de agrotóxicos em atividades rurais, na região de Atibaia, SP/ Brasil. 2008. 158f. Dissertação (Mestrado) - Universidade de São Paulo, São Paulo, 2008.

MATHEW, S.M.; GOPOLAKRISHNAN, P.K.; PETER, K.V. Compatibility among Cucumis melo varieties inodorus, conomon, flexuosus, momordica and utilissimus. Cucurbit Genetics Cooperative Report, v.9, p.78-80. 1986.

NACHREINER, M.L.; BOTEON, M.; PAULA, T.S. Sistema Agroindustrial do melão: Mossoró versus Juazeiro. Centros de Estudos Avançados em Economia Aplicada. CEPEA/ESALQ/USP, 2002.

NEVES, E.M.; DAYOUB, M.D.S. Análise da demanda por defensivos pela fruticultura brasileira. Revista Brasileira de Fruticultura, v. 24, n3. 2002. p.694-696.

NICOLAS, M. Z. et al. El Melon. Madrid: Ediciones Mundi-Prensa, 1989. 173p.

NOSSO FUTURO COMUM. Comissão Mundial Sobre Meio Ambiente e Desenvolvimento. 2 ed. Rio de Janeiro: Editora da Fundação Getúlio Vargas, 1991.

NUNES, E.M.; FELIPII, E.E. GODEIRO, K.F. Agronegócio, Estado e Meio Ambiente na Economia Potiguar: uma visão crítica. In: Encontro da ANPPAS. 2006. Brasília-DF. Anais, 2006. 


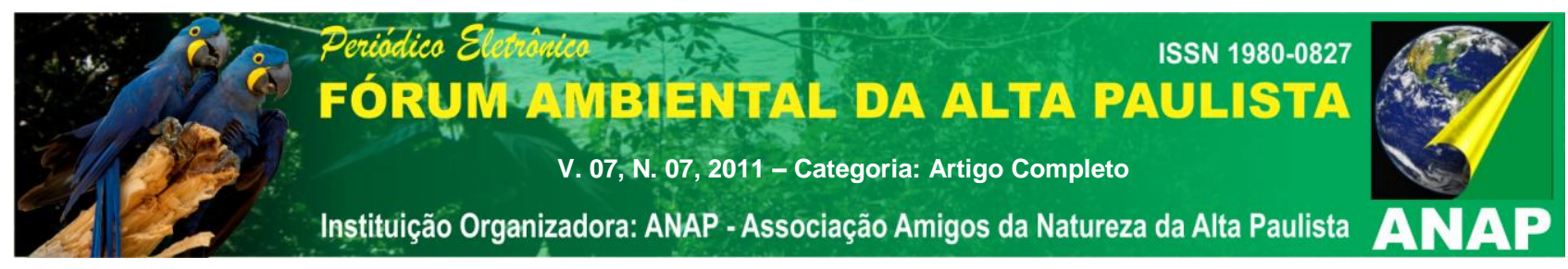

OLIVEIRA, M. de. Gêneses, classificação e extensão de solos afetados por sais. In GHEYI, H.R.; QUEIROZ, J.E.; MEDEIROS, J.F. (Eds). Manejo e controle da salinidade na agricultura irrigada. Campina Grande: UFPB-SBEA. Cap.1, 1997. p.1-36.

PEDROSA, J.F. Cultura do melão. Mossoró: ESAM, 1997.50 p.

PEREIRA, J. A. Revista Hortifruitbrasil. 2009. Disponível em:

<http://www.cepea.esalq.usp.br/hfbrasil/edicoes/82/melao.pdf>. Acesso em: 10 jun. 2010.

RODRIGUÊS, K.K.R. da P. Índice para a classificação da qualidade da água para irrigação. 2010.97f. Dissertação (Mestrado em Irrigação e Drenagem) - Universidade Federal Rural do Semi-Árido, Mossoró/RN.2010.

SEYMOUR, G.B.; McGLASSON, W.B. Melons. In: SEYMOUR, G.B.; TAYLOR, J.E.; TUCKER, G.A. (ed.) Biochemistry of fruit ripening. Londres: Chapman \& Hall, 1993. p273-290.

SIMMONDS, N. W. (ed). Evolution of crop plants. Logman: London e New york. $1976.339 \mathrm{p}$.

WHITAKER, T.D.; DAVIS, G.N. Cucurbits, Botany, Cultivation and utilization. New York, Intersciense Publishorts, 1962. 